\title{
Role of lipids on elongation of the preimplantation conceptus in ruminants
}

\author{
Eduardo S Ribeiro ${ }^{1}$, José E P Santos ${ }^{2}$ and William W Thatcher ${ }^{2}$ \\ ${ }^{1}$ Department of Animal Biosciences, University of Guelph, Guelph, Ontario, Canada and ${ }^{2}$ Department of Animal \\ Sciences and DH Barron Reproductive and Perinatal Biology Research Program, University of Florida, Gainesville, \\ Florida, USA
}

Correspondence should be addressed to E S Ribeiro; Email: eribeiro@uoguelph.ca

\begin{abstract}
Elongation of the preimplantation conceptus is a prerequisite for successful pregnancy in ruminants and depends on histotroph secretion by the endometrium. Lipids are an essential component of the histotroph, and recent studies indicate that lipids have important roles in the elongation phase of conceptus development. The onset of elongation is marked by dynamic changes in the transcriptome of trophectoderm cells, which are associated with lipid metabolism. During elongation, the trophectoderm increases transcript expression of genes related to uptake, metabolism and de novo biosynthesis of fatty acids and prostaglandins. Expression of the gene PPARG increases substantially, and activation of the transcription factor PPARG by binding of lipid ligands appears to be crucial for the coordination of cell biology during elongation. Lipids accumulated in the epithelial cells of the endometrium during diestrus are likely the most important source of fatty acids for utilization by the conceptus and become available in the uterine lumen through exporting of exosomes, microvesicles, carrier proteins and lipoproteins. Targeting of uterine lipid metabolism and PPARG activity during preimplantation conceptus development through nutraceutical diets may be a good strategy to improve pregnancy survival and reproductive efficiency in ruminants.

Reproduction (2016) 152 R115-R126
\end{abstract}

\section{Introduction}

Elongation of the conceptus is a prerequisite for successful implantation and survival of pregnancy in ruminants. In cattle, the hatched blastocyst remains detached in the uterine lumen and forms an ovoid conceptus by day 13 of development. Elongation starts around day 14, when the approximately $1 \mathrm{~mm}$ ovoid conceptus starts to elongate by rapid proliferation and reorganization of trophectoderm cells, and becomes a filamentous structure of approximately $200 \mathrm{~mm}$ by day 17 . Implantation occurs sequentially around day 20 and requires differentiation of trophectoderm mononuclear cells into binucleated cells, and the apposition with adhesion of the elongated conceptus to the luminal epithelium of the endometrium (Wooding 1992). Concurrent with elongation, the highly active trophectoderm cells secrete bioactive products that affect endometrial physiology, establishing a complex crosstalk between the two tissues that coordinate critical events for pregnancy recognition and maintenance of a functional corpus luteum, formation of a functional placenta, and survival of pregnancy to term (Spencer et al. 2004).

Conceptus elongation depends on histotroph secretion by the glandular epithelium of the endometrium. Uterine gland knockout in ewes resulted in the development of ovoid conceptuses, but precluded their elongation and survival (Gray et al. 2001). The uterine histotroph is a rich combination of molecules including saccharides, proteins, amino acids, lipids, ions, growth factors and cytokines that are fundamental for early embryo development in all mammals, but are especially important for ruminants whose implantation and formation of the epitheliochorial placenta occurs relatively late in development (Carter 2012). Conceptus cells use these molecules for nutrition, homeostasis and cell signaling. Although not often recalled as part of the histotroph, lipids are an essential component of cells, with structural and bioactive properties, and their role on conceptus development during the elongation phase have been the focus of recent studies. This review summarizes the current information on the potential roles of lipids during elongation of the ruminant preimplantation conceptus, and the associated implications.

\section{Evidence for the importance of lipids on elongation of the preimplantation ruminant conceptus}

Elongation of the preimplantation conceptus is complex and not elucidated completely. Little is known on how the conceptus senses and responds to the histotroph 
components, and it is uncertain what triggers the initial increase in proliferation and reorganization of trophectoderm cells. Interestingly, the time of the onset of elongation varies among animals. Transcervical uterine flushings of single-ovulating dairy cows on day 15 after artificial insemination resulted in the recovery of conceptuses ranging from 1 to $60 \mathrm{~mm}$ in length (Ribeiro et al. 2016a). Considering the fast speed of the elongation process, Ribeiro and coworkers (2016a) used the range in size of the recovered conceptuses to characterize changes in cell biology occurring in a short and important window of development, the onset of elongation. They categorized conceptuses as ovoid (1-4 mm), tubular (5-19 mm) or filamentous (20-60 mm) and compared their transcriptomes. As expected, substantial differences among the three groups were observed, which revealed important biological events associated with the elongation process and how it is coordinated.

Overall, 1611 transcripts were differently expressed in at least one out of the three pairwise comparisons. A total of 667 transcripts were expressed differently between ovoid and tubular, 404 between tubular and filamentous, and 1441 between ovoid and filamentous conceptuses. Functional analyses of the data revealed that lipid metabolism was one of the top molecular and cellular functions associated with the differentially expressed genes, involving at least 132 genes with known annotation and linkage to the specific function (Fig. 1). Within those upregulated as the conceptus transitioned from ovoid to filamentous were genes involved with lipid uptake (SCARB1, SCL27A6, SCL27A2), lipid droplet formation (PLIN2), activation (ACSL3, ACSL6, ACSS2, CRAT) and oxidation (ABCD3, ACOT8, ACOT4, ACOX1, ALDH3A2) of fatty acids, biogenesis of peroxisomes (CAT, PEX11A), desaturation (SCD, FADS2, FADS1) and elongation (TECR) of fatty acids, mobilization of membrane phospholipids (PLA2G7, PLA2G12A), biosynthesis of phospholipids (AGPAT9, AGPAT3, DGKD, GPAM, LPCAT3, LPCAT1, MOGAT1, PLCL2, SLC37A1, STARD10) and prostaglandins (AKR1A1, PTGES, PTGIS, PTCS2), and transport of prostaglandins (SLCO2A1) and other lipids metabolites (ABCG2, SLC10A1, SLC37A1, STARD10).

Among genes related to lipid metabolism, peroxisome proliferator-activated receptor gamma (PPARG) seemed to play important roles in elongation for numerous reasons. First, there was a substantial increase in transcript expression of PPARG during the onset of elongation (Fig. 2A); second, the functional analysis pointed PPARG as an important upstream regulator of the transcriptome changes observed (Fig. 3); third, level of expression of PPARG was correlated highly with the level of expression of several other genes known to influence conceptus development or lipid metabolism (Fig. 2B, C, D and Supplementary Table 1, see section on supplementary data given at the end of this article); and fourth, PPARG is known to have relevant biological functions in developmental biology. Peroxisome proliferator-activated receptors are a family of nuclear receptors that function as ligand-dependent transcription factors controlling a wide variety of biological processes in several tissues, including the placenta (Berger \& Moller 2002, Wieser et al. 2008).

Initially, PPARs were described as orphan receptors, with lipids such as polyunsaturated fatty acids, prostanoid metabolites, and constituents of oxidized low-density lipoproteins later identified as natural ligands of PPARs (Forman et al. 1997, Nagy et al. 1998). Binding of ligand causes conformational changes in the PPARG that facilitates the formation of heterodimers with retinoid $X$ receptor. The two nuclear receptors then bind to PPAR response elements (PPRE) in regulatory regions of target genes, influence transcription and, consequently, the biology of cells (Costa et al. 2010). Interestingly, genetic ablation of PPARG in mice caused embryonic lethality because of placental defects (Barak et al. 1999). Reconstitution of PPARG null embryos with wild-type placenta via chimeric aggregation corrected the defects and rescued embryo development. This confirmed the direct causative relationship of PPARG deficiency with placenta defects. Subsequent research demonstrated that PPARG was essential for uptake and metabolism of fatty acids, cell differentiation, and vascularization in the developing placenta (Schaiff et al. 2006, 2007, Fournier et al. 2011, Shalom-Barak et al. 2012). Low expression or low transcription factor activity of PPARG was suggested as a potential contributor for the occurrence of preeclampsia in women, a major cause of maternal and perinatal mortality (McCarthy et al. 2011a,b).

As in mice and humans, PPARG and lipid metabolism seems also to be critical for placentation of ruminants, particularly during preimplantation conceptus elongation. Agreeing with the findings from Ribeiro and coworkers (2016a) in cattle, a loss-of-function study demonstrated that PPARG regulates conceptus elongation in sheep (Brooks et al. 2015). Intrauterine infusion of morpholino antisense oligonucleotides for PPARG, which inhibit mRNA translation and protein expression, using osmotic pumps and starting before the time of conceptus elongation resulted in the recovery of growth-retarded conceptuses. The abnormal phenotype was not observed for conceptuses recovered from ewes treated with the intrauterine infusion of the designed control or PPAR-delta morpholinos. The latter two groups of ewes presented elongated filamentous conceptuses of expected size and morphology for the stage of development. As a consequence of their abnormal development, the treated conceptuses with knockdown PPARG had a reduced secretion of interferon-tau (IFNT) and prostaglandins in utero, which affected endometrium physiology.

Brooks and coworkers (2015) also evaluated the binding sites of PPARG in ovine conceptus cells by 


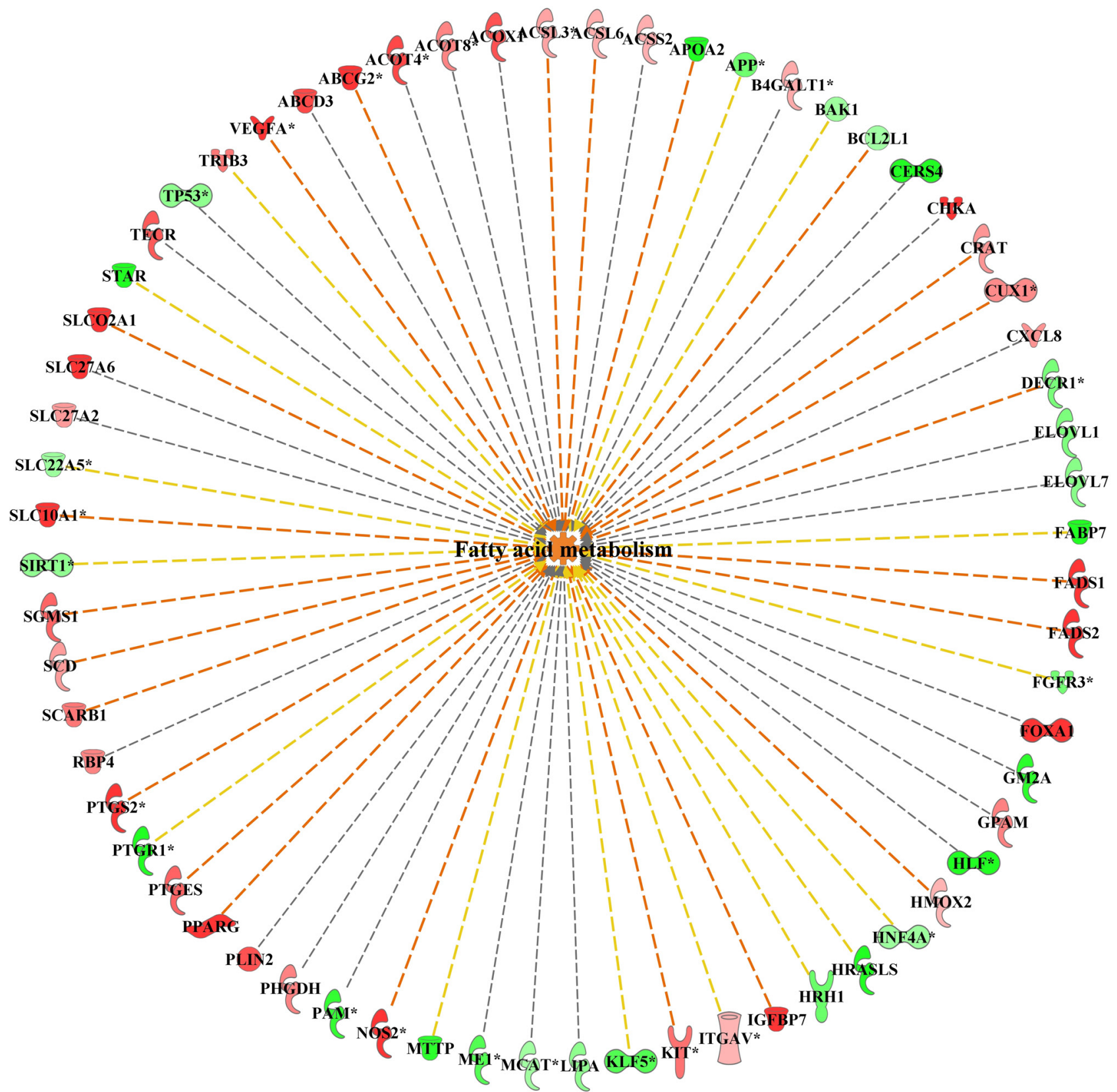

Figure 1 Lipid metabolism as a downstream effect of transcriptome changes observed in bovine conceptus at onset of elongation. Red denotes genes upregulated and green denotes genes downregulated in elongation. Orange and blue lines represent predicted increased and predicted decreased activation, respectively. Gray line represents effect not predicted. Yellow line represents inconsistences between the state of downstream molecule and the literature reference. Figure was generated using the Ingenuity Pathway Analyses software with data from Ribeiro and coworkers (2016a).

chromatin immunoprecipitation and sequencing. They identified 1833 bound segments of DNA within 10,000 bp of gene regions, thus with potential regulatory function. From those PPARG target genes, 1066 genes had transcript expression in ovine conceptus cells detected by RNA sequencing. Lipid biosynthesis and metabolism were the main biological processes enriched in the functional analyses of these genes. Out of the 1066 genes reported by Brooks and coworkers (2015), 824 are represented in the Affymetrix GeneChip platform used for bovine conceptuses by Ribeiro and coworkers (2016a). From those, 729 genes were expressed in the elongating bovine conceptuses, 105 were found to be expressed differently during elongation and 48 had expression highly correlated with the expression of PPARG. Among the latter are SLC27A6, ABCG2, MOGAT1, LPCAT1, LPCAT3, FADS1, FADS2, AGPAT3, AGPAT9 and ACSL6, which are critical genes for the 

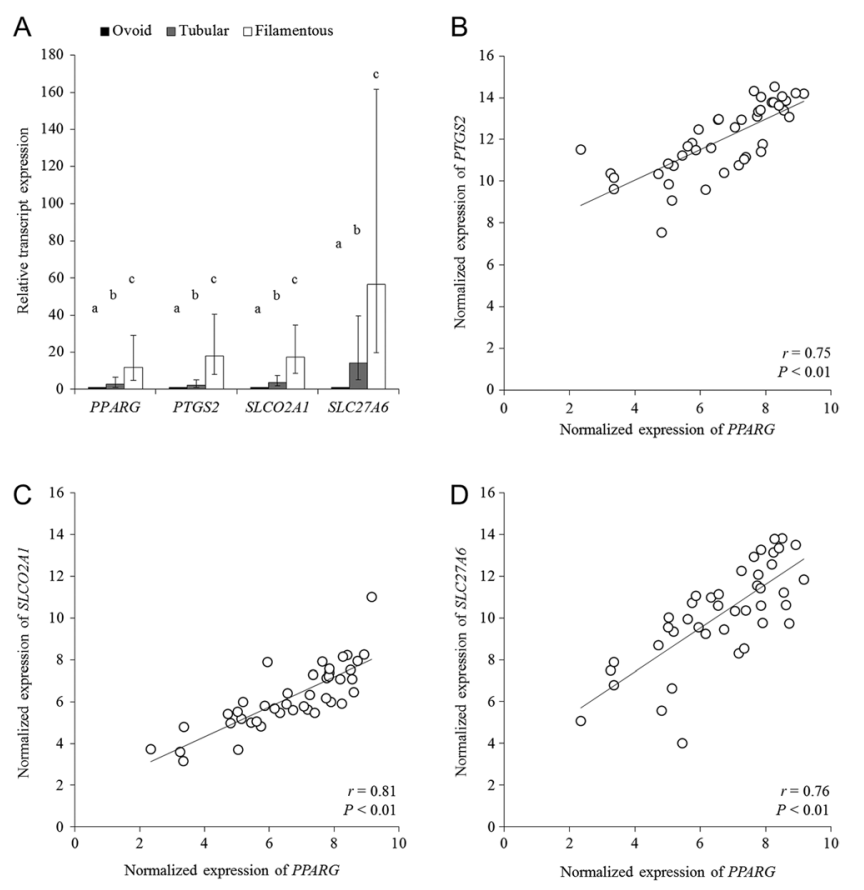

Figure 2 Transcript expression of PPARG, PTGS2, SLCO2A1 and SLC27A6 in conceptuses recovered from single-ovulating lactating cows on day 15 after breeding according to size/morphology of the conceptus categorized in ovoid (1-4 mm), tubular (5-19 mm) and filamentous ( $20-60 \mathrm{~mm}$ ), and analyzed by RTPCR (Panel A), and scatterplots of normalized expression of PTGS2, SLCO2A1 and SLC27A6 against normalized expression of PPARG (Panel B, C and D) in 42 conceptuses analyzed by microarray. In panel $\mathrm{A}$, ovoid conceptuses were used as the reference group for comparison, and the error bars represent the $95 \%$ confidence limits. Within gene, bars with different letters $(\mathrm{a}, \mathrm{b}, \mathrm{c})$ differ $(P<0.05)$. Data from Ribeiro and coworkers (2016a).

uptake, activation, synthesis and modification of fatty acids. Altogether, these findings suggest an important role of lipids during the process of elongation of the preimplantation conceptus in ruminants.

\section{Utilization of lipids by the elongating conceptus}

The nature of the process of conceptus elongation per se indicates a high demand for lipids. The biomass of the conceptus increases substantially during elongation. The mean \pm S.E.M. of the wet weight of bovine conceptuses was described as $12.2 \pm 1.9 \mathrm{mg}$ on day 16 of development (Lewis et al. 1982), $100 \pm 27.9 \mathrm{mg}$ on day 17 (Meier et al. 2011) and 238.6 $\pm 35.2 \mathrm{mg}$ on day 19 (Lewis et al. 1982). The rapid remodeling and proliferation of cells require lipids for syntheses of plasmalemma and organelles membranes, which must be sufficed by the uptake of lipids from the uterine lumen and from de novo biosynthesis of phospholipids. Expression of genes related to uptake of lipids from extracellular space, such as fatty acid transporters and scavenger receptors, and genes related to biosynthesis and modification of fatty acids, such as acyl-CoA synthetases and fatty acid desaturases, increase substantially during the onset of elongation (Ribeiro et al. 2016a). Activity of these proteins is important for providing the needed lipids for cellular replication and biology. They also determine the profile of fatty acids incorporated into the membranes and available in the intracellular space for regulation of cellular processes, which influence cell membrane function and cellular metabolism respectively. The preimplantation human embryo actively takes up individual fatty acids with preference for polyunsaturated fatty acids leading to accumulation of linoleic acid and other unsaturated fatty acids in place of saturated fatty acids as the conceptus develops (Haggarty et al. 2006).

Fatty acids also provide energy to support the requirements of the proliferating tissue. In addition to the rapid proliferation of cells, trophectoderm cells at elongation are very active and secrete considerable amounts of bioactive factors, which also require energy to be synthetized. Lipids could be used by conceptus cells for oxidation and generation of ATP, as well as for precursors of lipid derivatives such as eicosanoids, which are produced abundantly by the conceptus at this stage of development. The use of fatty acids as an energy source has the advantage of producing 2.3 and 1.7 times the caloric value per unit of mass compared with carbohydrates and proteins respectively. In addition, long-chain fatty acids can undergo peroxisomal oxidation, which generates smaller acyl chains that can be used for mitochondrial oxidation or for biosynthesis of specific phospholipids, and also byproducts such as reactive oxygen species that are important for cell signaling and differentiation (Ray et al. 2012). In fact, the level of expression of genes related to peroxisome formation, activation and oxidation of fatty acids increase during the onset of elongation in the bovine conceptus (Ribeiro et al. 2016a).

Trophectoderm of elongating conceptuses have a great demand for arachidonic acid or its precursors for production of eicosanoids. Bovine conceptuses on day 16 of development produced on average $350 \mathrm{ng}$ of prostaglandins per mg of tissue in 24-h period of in vitro incubation (Lewis et al. 1982). In fact, the amount of prostaglandins in the uterine lumen of pregnant cows and pregnant ewes is much greater than those observed in control cyclic females at the same stage of the estrous cycle, and the difference is explained by the amount of conceptus-derived prostaglandins (Lewis et al. 1982, Ulbrich et al. 2009, Spencer et al. 2013). In terms of transcript expression, genes related with supply of precursors and synthesis of prostaglandins increase substantially during the onset of elongation, and were highly correlated with the expression of PPARG (Fig. 2B and Supplementary Table 1; Ribeiro et al. 2016a).

Lipids are also important for cell signaling (Fernandis \& Wenk 2007) and for subcompartmentalization of cell membranes (Lingwood \& Simons 2010), with a broad variety of potential roles during conceptus elongation. 


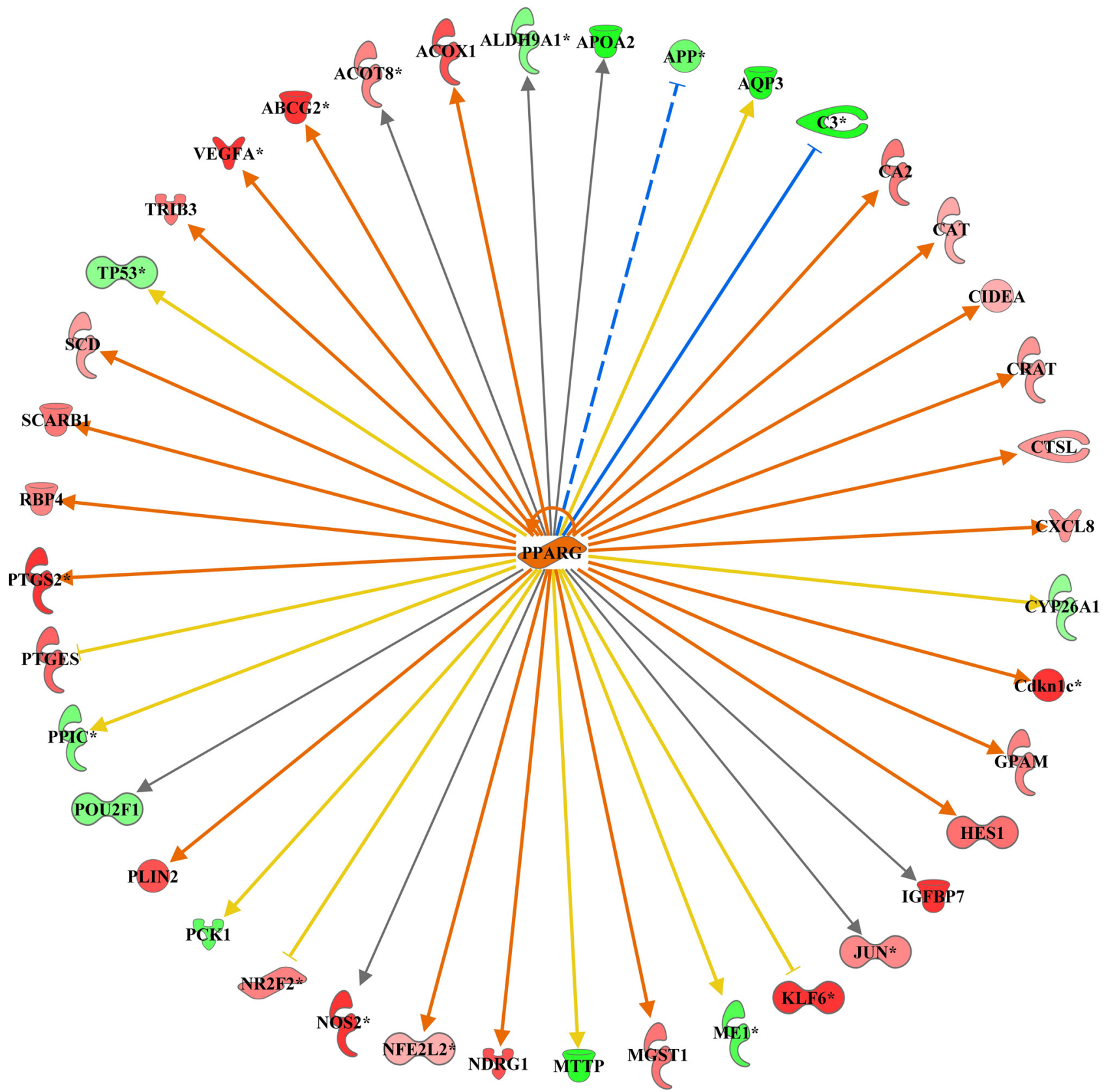

Figure 3 Peroxisome proliferator-activated receptor gamma (PPARG) as upstream regulator of transcriptome changes observed in bovine conceptus at onset of elongation. Red denotes genes upregulated and green denotes genes downregulated in elongation. Orange and blue lines represent predicted increased and predicted decreased activation, respectively. Solid and dashed lines imply on direct and indirect relationships, respectively. The pointed and blunted arrowheads represent activating and inhibitory relationships, respectively. Gray line represents effect not predicted. Yellow line represents inconsistences between the state of downstream molecule and the literature reference. Figure was generated using the Ingenuity Pathway Analyses software with data from Ribeiro and coworkers (2016a).

The best examples would be the eicosanoid signaling and PPARG activation. Prostaglandins have intracrine, autocrine and paracrine functions in conceptus and endometrium cells, which express both membrane and nuclear receptors for prostaglandins (Arosh et al. 2004, Cammas et al. 2006, MacLaren et al. 2006, Dorniak et al. 2011, 2012, Spencer et al. 2013). Moreover, transport of prostaglandins across cell membranes is performed by a transporter, which is expressed by both conceptus and endometrium cells (Banu et al. 2003, Ribeiro et al. 2016a). In fact, transcript expression of the prostaglandin transporter (SLCO2A1) in bovine conceptus cells increased with the onset of elongation (Fig. 2C; Ribeiro et al. 2016a). As mentioned herein, prostaglandins are natural ligands of PPARs (Forman et al. 1997) and, therefore, intracrine and paracrine 
effects of prostaglandins in conceptus and endometrium cells can be mediated by PPAR coordination of gene expression. Furthermore, intrauterine infusion of prostaglandins in ewes induced expression of several genes in the endometrium that are known to stimulate trophectoderm cell proliferation and migration within the uterine lumen during the elongation phase (Dorniak et al. 2011, Spencer et al. 2013). Intrauterine infusion of meloxicam, a specific inhibitor of prostaglandinendoperoxide synthase activity, in pregnant ewes reduced the amount of prostaglandins in the uterine fluid and precluded conceptus elongation (Dorniak et al. 2011).

Other lipids such as lysophosphatidic acid (LPA) also have been suggested to play an important role in cell signaling during conceptus development in ruminants in combination with prostaglandins (Liszewska et al. 2009, Woclawek-Potocka et al. 2009). The amount of LPA in the uterine fluid of pregnant ewes increased during the elongation phase, and the supplementation of LPA in culture medium of trophectoderm cells increased cell proliferation, remodeling of cytoskeleton and prostaglandin secretion (Liszewska et al. 2009). Autotaxin, an ectoenzyme responsible for synthesis of most LPA in extracellular body fluids (Barbayianni et al. 2015), was shown to be expressed in both conceptus and endometrium cells of ewes (Liszewska et al. 2009) and cows (Woclawek-Potocka et al. 2009, Ribeiro et al. 2016a). Thus, both the endometrium and the elongating conceptus can contribute for the amount of LPA available in the uterine lumen during the elongation phase. The LPA acts in conceptus and endometrium cells through a group of $\mathrm{G}$ protein-coupled receptors that induce multiple intracellular signals (Liszewska et al. 2009, 2012, Woclawek-Potocka et al. 2009). Nonetheless, PPARG has been identified as an intracellular receptor for LPA (McIntyre et al. 2003) and, therefore, it might contribute for LPA signaling in ruminant conceptus during elongation. Interestingly, McIntyre and coworkers (2003) suggested that the type of acyl residue in the LPA molecule would not influence significantly the activation of PPARG, but the anionic phosphoryl group would be the primary determinant of PPARG activation.

\section{Source and delivery of lipids for conceptus utilization}

Ribeiro and coworkers (2016a) characterized the metabolome of the uterine fluid collected on day 15 after artificial insemination in lactating dairy cows. Several lipids were detected by mass spectrophotometry in the uterine fluid of bred cows on day 15 after insemination, and considerable differences were observed between pregnant and nonpregnant cows. Pregnant cows had reduced amounts of arachidonate, but increased amounts of three arachidonate-derivative molecules, prostaglandins, 15-hydroxyeicosatetraenoic acid and anandamide, compared with nonpregnant cows. The three arachidonate-derivative molecules have been demonstrated to be ligands/activators of PPARG (Brezinski \& Serhan 1990, Forman et al. 1997, Nagy et al. 1998, O'Sullivan 2007) and may play an important role coordinating gene expression and biology of conceptus cells during elongation. Moreover, 9,12,13-TriHOME, a trihydroxy metabolite of linoleic acid, had a greater concentration in the uterine fluid of pregnant cows. The 9,12,13-TriHOME also binds to PPARG and has potential roles on controlling arachidonic acid and prostaglandin biosynthesis (Funk et al. 1985), Additional differences regarding fatty acids in the uterine fluid included lower concentration of oleic acid and greater concentrations of stearic acid derivatives in pregnant cows. Finally, lipoate had the largest difference in abundance between pregnant and nonpregnant cows, with a 14-fold increase in pregnant cows. Lipoic acid is a dithiol compound synthesized from octanoic acid with a high redox potential and antioxidative effects that works as a cofactor for multiple enzymes (Shay et al. 2009). Overall, the metabolomics investigation demonstrated that lipids are available in the uterine fluid to be used by conceptus cells and the presence of an elongating conceptus causes changes in the lipid profile that may be associated with important biological events occurring during elongation.

The endometrium is the most likely source of lipids for conceptus utilization, although direct transfer of lipids from uterine blood circulation to the uterine lumen cannot be discarded. Pioneer research demonstrated important variation in the amount of lipid droplets in the endometrium epithelium according to the phase of estrous cycle in both cows (Skjerven 1956, Marinov \& Lovell 1968, Wordinger et al. 1977) and ewes (Brinsfield \& Hawk 1973, Boshier et al. 1987). In both species, the amount of lipid droplets in the endometrial epithelium is low during the metestrus and increases throughout the diestrus phase, being maximal in the phase corresponding to the time of the onset of conceptus elongation. A classical study by Brinsfield and Hawk (1973) demonstrated that progesterone is the main hormone controlling lipid accumulation in the endometrium. The increase in lipid droplets in the endometrial epithelium was parallel with the development of the corpus luteum during the estrous cycle, and progesterone supplementation in ovariectomized ewes induced accumulation of lipids in the endometrium that was comparable to the accumulation of lipids observed in a spontaneous estrous cycle. Therefore, it is reasonable to speculate that the accumulation of lipids in the endometrium with exposure to progesterone may act as a mechanism to supply lipids for the elongating conceptus to meet the demand of fatty acids for cell replication, signaling and metabolism. In nonpregnant females, the accumulated lipids during late diestrus would be 
used for the production of luteolytic prostaglandins by the endometrium at the end of diestrus (McCracken et al. 1999) or for unknown estradiol effects in the endometrium during the follicular phase of the estrous cycle (Brinsfield \& Hawk 1973).

The amount of lipid droplets in epithelial cells of the endometrium in ewes was found to be reduced by the presence of a conceptus (Boshier et al. 1987, Meier et al. 1997), which suggests increased utilization of such lipids by the presence of the conceptus. Moreover, differences in lipid profile in the endometrium at late diestrus between pregnant and nonpregnant ewes (Meier et al. 1997), pregnant and nonpregnant cows (Bilby et al. 2006, Meier et al. 2009) and between gravid and nongravid horns of pregnant cows (Meier et al. 2011) have been reported, although results are inconsistent. The variability in results may be attributed to differences in experimental design and methods utilized, especially for sampling of the endometrium and analyses used for lipids measurements. The accumulation of lipids occurs mainly in the luminal epithelium and superficial glandular epithelium in both cows (Wordinger et al. 1977) and ewes (Brinsfield \& Hawk 1973). Little or no lipid droplets were observed in the deep glandular epithelium and stromal cells of the endometrium (Brinsfield \& Hawk 1973, Wordinger et al. 1977). Thus, sampling the entire endometrium without discerning the distinct cellular layers might distort accurate identification and quantification of fatty acids and other lipids. Future studies may have to focus on lipid composition of specific endometrial cell types.

The biological mechanisms by which lipids leave the endometrium, reach and are taken up by the conceptus cells still are not elucidated. Considerable amount of extracellular vesicles, exosomes and microvesicles are detected in the uterine fluid of multiple species, including ruminants (Racicot et al. 2012, Ng et al. 2013, Burns et al. 2014, Ruiz-González et al. 2014). These vesicles are secreted by both the endometrium and the conceptus cells and serve as a communication mechanism between the two tissues (Ng et al. 2013). Most research investigating uterine extracellular vesicles have focused on their cargo, which contain a combination of important molecules for conceptus development such as proteins, mRNAs, miRNAs and endogenous retrovirus (Racicot et al. 2012, Burns et al. 2014, Ruiz-González et al. 2014). Nonetheless, the extracellular vesicles are composed of lipids and might represent an important source of fatty acids for utilization by the trophectoderm cells during elongation. Both exosomes and microvesicles are formed by a lipid bilayer membrane, which is incorporated by target cells. Microvesicles are derived from shedding of the plasma membrane and, consequently, their lipid profile is similar to that of the plasma membrane of the original cells. Exosomes, however, are formed and secreted in the late endosome and have particular features. Sorting of lipids occurs during exosome formation and, in addition to the phospholipid bilayer membrane, exosomes also transfer specific lipids (e.g. arachidonic acid), lipids metabolites (e.g. prostaglandins), phospholipases and other enzymes for lipid metabolism of their cargo (Subra et al. 2010, Record et al. 2014).

Carrier proteins and lipoproteins provide other potential mechanisms for transport of lipids from the endometrium to the conceptus, but their presence in the uterine fluid and relevance during the elongation phase are not well characterized. In blood plasma, the volume of lipids carried by carriers and lipoproteins are more significant than the volume of lipids carried by extracellular vesicles (Record et al. 2014). If the uterine fluid resembles blood plasma in this regard, carrier proteins and lipoproteins may be more important than extracellular vesicles regarding lipid supply to conceptus. Albumin, for example, was the most abundant protein in the uterine fluid of pregnant heifers on day 16 of the estrous cycle in a proteomic study (Forde et al. 2014). Moreover, pregnant ewes had greater concentration of apolipoprotein-A1, the main protein component of high-density lipoprotein, in the uterine fluid than control cyclic ewes on day 16 of the estrous cycle (Koch et al. 2010). High-density lipoprotein is the major lipoprotein transporting lipids in ruminants and the major method to transfer fatty acids, cholesterol and cholesteryl esters among tissues through the bloodstream in wellfed animals (Cordle et al. 1985). Forde and coworkers (2014) and Koch and coworkers (2010) also detected the presence of fatty acid binding proteins in the uterine fluid, which are likely needed to keep the apolar lipids in suspension in the uterine lumen. Moreover, cells of elongating bovine conceptuses express transcripts for lipoprotein receptors, scavenger receptors and fatty acid transporters (Ribeiro et al. 2016a), thereby suggesting an active system for lipid transport and uptake by the conceptus. In fact, the transcript expression of the longchain fatty acid transport protein 6 (SCL27A6) increased substantially during the onset of elongation in bovine conceptuses, and it was highly correlated with the expression of PPARG (Fig. 2D; Ribeiro et al. 2016a). Moreover, a PPRE bound by PPARG was found in the gene region of SCL27A6 in elongating ovine conceptuses cells (Brooks et al. 2015).

\section{Potential implications and applications}

Reproduction is a critical component of any ruminant production system, and optimization of reproductive efficiency is a necessity to maintain farms economically viable and sustainable (Morris 2009, Rodgers et al. 2012, Ribeiro et al. 2012). Pregnancy loss in ruminants, however, is substantial and impairs reproductive efficiency, causing significant economic losses (Santos et al. 2004, Dixon et al. 2007). Most pregnancy losses 
occur at early stages of embryonic development, including the elongation phase. In lactating dairy cows, it has been estimated that approximately one-third of viable blastocysts fail to elongate and survive by the end of the fourth week of development (Ribeiro et al. 2016b).

Although considerable progress has been made on the understanding of early pregnancy biology in ruminants, only modest progress has been made on the understanding of developmental failures and on the design of strategies to reduce embryonic mortality. For instance, pregnancy per AI in dairy cows in USA has not changed significantly over the last 15 years and advances in reproductive efficiency observed in the same period were obtained mainly by improving management strategies (Bisinotto et al. 2014). Further improvements in reproductive efficiency of ruminant production systems will require the development of strategies to minimize embryonic mortality, which in turn will require a better elucidation of critical events in developmental biology. Based on the evidences presented herein, lipid metabolism during the preimplantation stages of development might be an important target for better elucidation of its biology and potential development of nutraceutical or pharmaceutical methods to improve conceptus survival in ruminants.

Lipids represent a small but important component of ruminant diets. Lipid content of diets is normally around $2-3 \%$, but fat supplementation is commonly used and is intended for increasing the energy density of the diet and for the utilization of nutraceutical properties of specific fatty acids. Different strategies of fat supplementation have demonstrated benefits in production, health and reproduction of ruminants (Staples et al. 1998, Santos et al. 2008, Silvestre et al. 2011, Rabiee et al. 2012, Greco et al. 2015, Rodney et al. 2015). The benefits observed often are not accounted solely to the increase in energy density of the diet and resulting caloric intake, but better explained by the type of fatty acids supplemented (Staples et al. 1998). More recently, research on fat supplementation has focused mainly in the supplementation of particular fatty acids such as those belonging to the omega- 3 and omega- 6 families, some of which are considered essential. Rumen microbial biohydrogenation of the unsaturated acyl chains, however, constitutes a challenge for supplementation of unsaturated fatty acids, as the profile of fatty acids absorbed in the gut are distinct from the one supplied in the diet. Nonetheless, technologies to reduce the availability of unsaturated fatty acids in the rumen decreases biohydrogenation and increase the delivery to the small intestine for absorption and subsequent delivery to tissues during the postabsorptive state (Theurer et al. 2009, Greco et al. 2015).

Manipulation of the dietary lipid content is not only capable of altering the fatty acids profile in tissues but could also change tissue physiology (Calder 2012). Feeding a diet rich in omega-3 fatty acids to cows increased the proportion of omega-3 fatty acids and reduced the proportion of arachidonic acid in the endometrium (Burns et al. 2003, Bilby et al. 2006), and resulted in a smaller prostaglandin response to an oxytocin challenge in late diestrus (Mattos et al. 2002). In general, fat supplementation generally improves reproduction in dairy cows (Rodney et al. 2015), and most benefits observed had been attributed to the noncaloric effects of fatty acids (Santos et al. 2008). Improvements resulted from greater pregnancy per insemination and smaller pregnancy losses after pregnancy diagnosis. The noncaloric effects include, but are not limited to, improved measures of immunity and smaller incidence of diseases, altered follicle development and oocyte quality, and improved uterine environment for pregnancy development. Isolation of the effects, however, is difficult considering that most studies evaluate long-term feeding strategies.

Regarding the impact of fatty acids on uterine biology, most research have focused on changing the profile of fatty acids in the endometrium with supplemental fat, aiming to reduce the proportion of prostaglandins precursors, especially arachidonic acid, and consequently reduce the capability of the endometrium to produce series-2 prostaglandins. The strategy would protect the corpus luteum from luteolytic prostaglandin, which is essential for pregnancy maintenance in ruminants. Nonetheless, considering the current knowledge of the biology of elongating conceptus and its demand for arachidonic acid and prostaglandins, the strategy might not be completely beneficial for conceptus development. In fact, luteolysis can be avoided by the presence of a healthy conceptus in the uterus and substantial secretion of IFN- $\tau$. Thus, the focus of fatty acid supplementation for improving uterine biology should shift from manipulating the production of luteolytic prostaglandin pulses to the discovery of the best fatty acid profile that supports conceptus development. However, further basic research is still needed for a holistic understanding of the accumulation or enrichment of lipids in the endometrium, their transfer from endometrium to the conceptus and their utilization by the conceptus. Targeting the activation of PPARG in trophectoderm cells might be a good strategy to enhance conceptus development.

Lipid composition in tissues also has a genetic component (Saatchi et al. 2013, Buchanan et al. 2015). The genomic era has revolutionized how we think about the potential for genetic control of phenotypes, and one cannot forget about the potential variation of endometrial fatty acids caused by genetics and its consequences for conceptus development and pregnancy survival to term. Moreover, the physiological state of the female could also impact lipid composition and metabolism in different tissues. Lactation, for example, causes dramatic changes in the metabolism of dairy cows (Thompson et al. 2012), and many of these changes are associated with reduced 
fertility of lactating cows compared with heifers. Valour and coworkers (2014) compared conceptus development and transcriptome of lactating dairy cows and heifers. Although no major differences were found in the size and morphology of the conceptuses, significant differences were observed in the transcriptome of the conceptus cells. Interestingly, lipid metabolism was one of the most important functions enriched by the differently expressed genes in the functional analysis of the data. For instance, conceptuses recovered from heifers had greater expression of genes related to prostaglandins biosynthesis (PTGES, PTGDS) than those recovered from early lactation cows. Inflammatory diseases postpartum might constitute another important example. Prostaglandins are important mediators of inflammation and therefore diseases might have consequences for lipid content in tissues and metabolism. Incidence of postpartum diseases is one of the major causes of reproductive failure in cattle. Cows that suffer inflammatory diseases postpartum have impaired conceptus development, greater incidence of pregnancy loss and reduced reproductive performance (Ribeiro et al. 2016b). Investigation of the impact of physiological states on lipid metabolism and composition in tissues might also contribute for the holistic understanding of the lipid contribution to developmental biology in ruminants.

\section{Conclusions}

Lipids are important for elongation of the ruminant preimplantation conceptus (Fig. 4). They are used

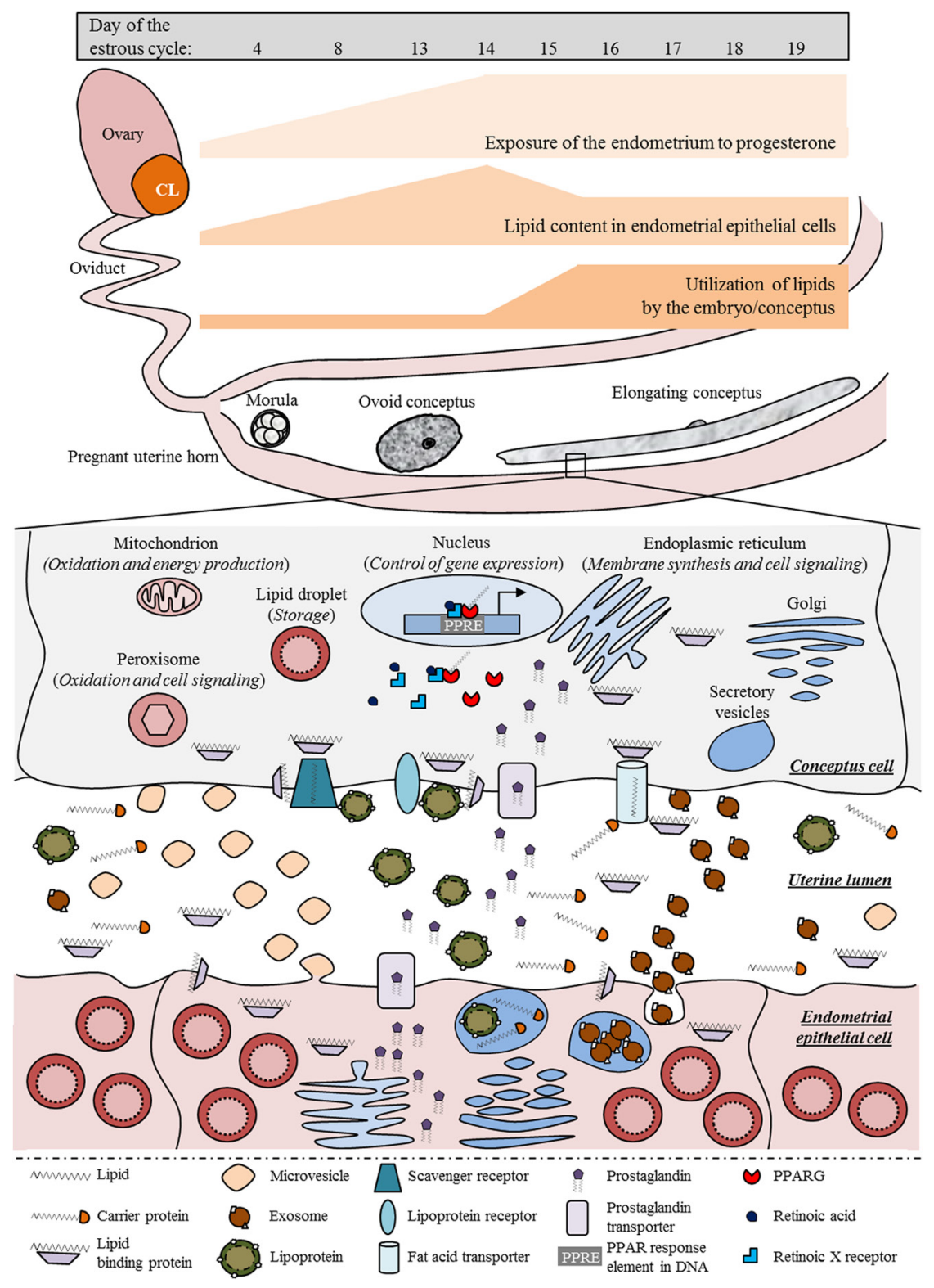

Figure 4 Schematic figure illustrating the working hypothesis model. Progesterone secreted by a matured corpus luteum during diestrus induces accumulation of lipids in the endometrial epithelial cells. Lipids accumulated in the endometrium are the most important source of fatty acids for utilization by the conceptus during elongation. Endometrium lipids are exported to the uterine lumen by exosomes, microvesicles, carrier proteins and lipoproteins, and incorporated by conceptus cells by fusion of membranes supported by receptors and fatty acids transporters. Lipids taken up by conceptus cells are essentially used for synthesis of cell membranes, energy production and cell signaling. Activation of PPARG by lipid ligands would be a major event for coordination of transcription and cell biology during elongation. 
by trophectoderm cells for nutrition, homeostasis, signaling and coordination of gene expression. Lipids accumulated in epithelial cells of the endometrium during diestrus are likely the most important source of fatty acids for utilization by the conceptus. Endometrium lipids are potentially exported to the uterine lumen by exosomes, microvesicles, carrier proteins and lipoproteins, and incorporated by conceptus cells by fusion of membranes supported by receptors and fatty acids transporters. Lipids could be used for oxidation, mitochondrial and peroxisomal, and generation of ATP, biosynthesis of membrane phospholipids and prostaglandins, and cell signaling. Activation of PPARG by lipid ligands would be a major event for coordination of transcription and cell biology during elongation. Targeting uterine lipid metabolism and PPARG activity during preimplantation development of ruminant conceptus through nutraceutical diets might constitute an important strategy to improve pregnancy survival and reproductive efficiency in ruminants.

\section{Supplementary data}

This is linked to the online version of the paper at http://dx.doi. org/10.1530/REP-16-0104.

\section{Declaration of interest}

The authors declare that there is no conflict of interest that could be perceived as prejudicing the impartiality of this review.

\section{Funding}

Financial support for some of the experiments by the authors was provided by grants from the Southeast Milk Inc. Checkoff Program (Belleview, FL), Virtus Nutrition LLC (Corcoran, CA), Arm and Hamer Animal Nutrition (Princeton, NJ) and by the National Institute of Food and Agriculture of the U.S. Department of Agriculture (Grant No. 2015-67015-23313, 2015).

\section{Acknowledgements}

The authors thank Drs Peter Hansen and Thomas Yang, University of Florida, for the insightful discussions in the subject of this review.

\section{References}

Arosh JA, Banu SK, Chapdelaine P \& Fortier MA 2004 Temporal and tissuespecific expression of prostaglandin receptors EP2, EP3, EP4, FP, and cyclooxygenases 1 and 2 in uterus and fetal membranes during bovine pregnancy. Endocrinology 145 407-417. (doi:10.1210/en.2003-1007)

Banu SK, Arosh JA, Chapdelaine P \& Fortier MA 2003 Molecular cloning and spatio-temporal expression of the prostaglandin transporter: A basis for the action of prostaglandins in the bovine reproductive system. PNAS 100 11747-11752. (doi:10.1073/pnas.1833330100)
Barak Y, Nelson MC, Ong ES, Jones YZ, Ruiz-Lozano P, Chien KR, Koder A \& Evans RM 1999 PPAR $\gamma$ is required for placental, cardiac, and adipose tissue development. Molecular Cell 4 585-595. (doi:10.1016/S10972765(00)80209-9)

Barbayianni E, Kaffe E, Aidinis V \& Kokotos G 2015 Autotaxin, a secreted lysophospholipase $\mathrm{D}$, as a promising therapeutic target in chronic inflammation and cancer. Progress in Lipid Research 58 76-96. (doi:10.1016/j.plipres.2015.02.001)

Berger J \& Moller DE 2002 The mechanisms of action of PPARs. Annual Review of Medicine 53 409-435. (doi:10.1146/annurev. med.53.082901.104018)

Bilby TR, Jenkins T, Staples CR \& Thatcher WW 2006 Pregnancy, bovine somatotropin, and dietary n-3 fatty acids in lactating dairy cows: III. Fatty acid distribution. Journal of Dairy Science 89 3386-3399. (doi:10.3168/ jds.s0022-0302(06)72375-x)

Bisinotto RS, Ribeiro ES \& Santos JEP 2014 Synchronisation of ovulation for management of reproduction in dairy cows. Animal 8 151-159. (doi:10.1017/S1751731114000858)

Boshier DP, Fairclough RJ \& Holloway H 1987 Assessment of sheep blastocyst effects on neutral lipids in the uterine caruncular epithelium. Journal of Reproduction and Fertility 79 569-573. (doi:10.1530/ jrf.0.0790569)

Brezinski ME \& Serhan CN 1990 Selective incorporation of (15S)hydroxyeicosatetraenoic acid in phosphatidylinositol of human neutrophils: agonist-induced deacylation and transformation of stored hydroxyeicosanoids. PNAS 87 6248-6252. (doi:10.1073/ pnas.87.16.6248)

Brinsfield TH \& Hawk HW 1973 Control by progesterone of the concentration of lipid droplets in epithelial cells of the sheep endometrium. Journal of Animal Science 36 919-922.

Brooks KE, Burns GW \& Spencer TE 2015 Peroxisome proliferator activator receptor gamma (PPARG) regulates conceptus elongation in sheep. Biology of Reproduction 92 42. (doi:10.1095/biolreprod.114.123877)

Buchanan JW, Reecy JM, Garrick DJ, Duan Q, Beitz DC \& Mateescu RG 2015 Genetic parameters and genetic correlations among triacylglycerol and phospholipid fractions in Angus cattle. Journal of Animal Science 93 522-528. (doi:10.2527/jas.2014-8418)

Burns PD, Engle TE, Harris MA, Enns RM \& Whittier JC 2003 Effect of fish meal supplementation on plasma and endometrial fatty acid composition in nonlactating beef cows. Journal of Animal Science $\mathbf{8 1}$ 2840-2846.

Burns G, Brooks K, Wildung M, Navakanitworakul R, Christenson LK \& Spencer TE 2014 Extracellular vesicles in luminal fluid of the ovine uterus. PLoS ONE 9 e90913. (doi:10.1371/journal.pone.0090913)

Calder PC 2012 Long-chain fatty acids and inflammation. Proceedings of the Nutrition Society 71 284-289. (doi:10.1017/S0029665112000067)

Cammas L, Reinaud P, Bordas N, Dubois O, Germain G \& Charpigny G 2006 Developmental regulation of prostacyclin synthase and prostacyclin receptors in the ovine uterus and conceptus during the peri-implantation period. Reproduction 131 917-927. (doi:10.1530/rep.1.00799)

Carter AM 2012 Evolution of placental function in mammals: the molecular basis of gas and nutrient transfer, hormone secretion, and immune responses. Physiological Reviews 92 1543-1576. (doi:10.1152/ physrev.00040.2011)

Cordle SR, Clegg RA \& Yeaman 1985 Purification and characterization of bovine lipoproteins: resolution of high density and low density lipoproteins using heparin-Sepharose chromatography. Journal of Lipid Research 26 721-725.

Costa V, Gallo MA, Letizia F, Aprile M, Casamassimi A \& Ciccodicola A 2010 PPARG: gene expression regulation and next-generation sequencing for unsolved issues. PPAR Research 2010 1-17. (doi:10.1155/2010/409168)

Dixon AB, Knights M, Winkler JL, Marsh DJ, Pate JL, Wilson ME, Dailey RA, Seidel G \& Inskeep EK 2007 Patterns of late embryonic and fetal mortality and association with several factors in sheep. Journal of Animal Science 85 1274-1284. (doi:10.2527/jas.2006-129)

Dorniak P, Bazer FW \& Spencer TE 2011 Prostaglandins regulate conceptus elongation and mediate effects of interferon tau on the ovine uterine endometrium. Biology of Reproduction 84 1119-1127. (doi:10.1095/ biolreprod.110.089979)

Dorniak P, Bazer FW, Wu G \& Spencer TE 2012 Conceptus-derived prostaglandins regulate endometrial function in sheep. Biology of Reproduction 87 9. (doi:10.1095/biolreprod.112.100487) 
Fernandis AZ \& Wenk MR 2007 Membrane lipids as signaling molecules. Current Opinion in Lipidology 18 121-128. (doi:10.1097/ MOL.0b013e328082e4d5)

Forde N, McGettigan PA, Mehta JP, O'Hara L, Mamo S, Bazer FW, Spencer TE \& Lonergan P 2014 Proteomic analysis of uterine fluid during the pre-implantation period of pregnancy in cattle. Reproduction 147 575-587. (doi:10.1530/REP-13-0010)

Forman BM, Chen J \& Evans RM 1997 Hypolipidemic drugs, polyunsaturated fatty acids, and eicosanoids are ligands for peroxisome proliferator-activated receptors $a$ and $\delta$. PNAS $94 \quad 4312-4317$. (doi:10.1073/pnas.94.9.4312)

Fournier T, Guibourdenche J, Handschuh K, Tsatsaris V \& EvainBrion D 2011 PPAR $\gamma$ and human trophoblast differentiation. Journal of Reproductive Immunology 90 41-49. (doi:10.1016/j.jri.2011.05.003)

Funk CD \& Powell WS 1985 Release of prostaglandins and monohydroxy and trihydroxy metabolites of linoleic and arachidonic acids by adult and fetal aortae and ductus arteriosus. Journal of Biological Chemistry $2607481-7488$.

Gray CA, Taylor KM, Ramsey WS, Hill JR, Bazer FW, Bartol FF \& Spencer TE 2001 Endometrial glands are required for conceptus elongation and survival. Biology of Reproduction 64 1608-1613. (doi:10.1095/ biolreprod64.6.1608)

Greco LF, Neves Neto JT, Pedrico A, Ferrazza RA, Lima FS, Bisinotto RS, Martinez N, Garcia M, Ribeiro ES, Gomes GC et al. 2015 Effects of altering the ratio of dietary n-6 to n-3 fatty acids on performance and inflammatory responses to a lipopolysaccharide challenge in lactating Holstein cows. Journal of Dairy Science 98 602-617. (doi:10.3168/ jds.2014-8805)

Haggarty P, Wood M, Ferguson E, Hoad G, Srikantharajah A, Milne E, Hamilton M \& Bhattacharya S 2006 Fatty acid metabolism in human preimplantation embryos. Human Reproduction 21 766-773. (doi:10.1093/humrep/dei385)

Koch JM, Ramadoss J \& Magness RR 2010 Proteomic profile of uterine luminal fluid from early pregnant ewes. Journal of Proteome Research $\mathbf{9}$ 3878-3885. (doi:10.1021/pr100096b)

Lewis GS, Thatcher WW, Bazer FW \& Curl JS 1982 Metabolism of arachidonic acid in vitro by bovine blastocysts and endometrium. Biology of Reproduction 27 431-439. (doi:10.1095/biolreprod27.2.431)

Lingwood D \& Simons K 2010 Lipid rafts as a membrane-organizing principle. Science 327 46-50. (doi:10.1126/science.1174621)

Liszewska E, Reinaud P, Billon-Denis E, Dubois O, Robin P \& Charpigny G 2009 Lysophosphatidic acid signaling during embryo development in sheep: involvement in prostaglandin synthesis. Endocrinology $\mathbf{1 5 0}$ 422-434. (doi:10.1210/en.2008-0749)

Liszewska E, Reinaud P, Dubois O \& Charpigny G 2012 Lysophosphatidic acid receptors in ovine uterus during estrous cycle and early pregnancy and their regulation by progesterone. Domestic Animal Endocrinology 42 31-42. (doi:10.1016/j.domaniend.2011.08.003)

MacLaren LA, Guzeloglu A, Michel F \& Thatcher WW 2006 Peroxisome proliferator-activated receptor (PPAR) expression in cultured bovine endometrial cells and response to omega-3 fatty acid, growth hormone and agonist stimulation in relation to series 2 prostaglandin production. Domestic Animal Endocrinology 30 155-169. (doi:10.1016/j. domaniend.2005.07.003)

Marinov U \& Lovell JE 1968 Cytology of the bovine uterine epithelium during the estrous cycle. American lournal of Veterinary Research 2913.

Mattos R, Staples CR, Williams J, Amorocho A, McGuire MA \& Thatcher WW 2002 Uterine, ovarian, and production responses of lactating dairy cows to increasing dietary concentrations of menhaden fish meal. Journal of Dairy Science 85 755-764. (doi:10.3168/jds. S0022-0302(02)74133-7)

McCarthy FP, Drewlo S, English FA, Kingdom J, Johns EJ, Kenny LC \& Walsh SK 2011a Evidence implicating peroxisome proliferator-activated receptor- $\gamma$ in the pathogenesis of preeclampsia. Hypertension 58 882887. (doi:10.1161/hypertensionaha.111.179440)

McCarthy FP, Drewlo S, Kingdom J, Johns EJ, Walsh SK \& Kenny LC 2011b Peroxisome proliferator-activated receptor- $\gamma$ as a potential therapeutic target in the treatment of preeclampsia. Hypertension 58 280-286. (doi:10.1161/hypertensionaha.111.172627)

McCracken JA, Custer EE \& Lamsa JC 1999 Luteolysis: a neuroendocrinemediated event. Physiological Reviews 79 263-324.
McIntyre TM, Pontsler AV, Silva AR, Hilaire AS, Xu Y, Hinshaw JC, Zimmerman GA, Hama K, Aoki J, Arai $\mathrm{H}$ et al. 2003 Identification of an intracellular receptor for lysophosphatidic acid (LPA): LPA is a transcellular PPAR $\gamma$ agonist. PNAS 100 131-136. (doi:10.1073/ pnas.0135855100)

Meier S, Trewhella MA, Fairclough RJ \& Jenkin G 1997 Changes in uterine endometrial phospholipids and fatty acids throughout the oestrous cycle and early pregnancy in the ewe. Prostaglandins, Leukotrienes and Essential Fatty Acids 57 341-349. (doi:10.1016/S0952-3278(97)90554-8)

Meier S, Peterson AJ, Mitchell MD, Littlejohn M, Walker C \& Roche JR 2009 Genetic strain and reproductive status affect endometrial fatty acid concentration. Journal of Dairy Science 92 3723-3730. (doi:10.3168/ jds.2009-2047)

Meier S, Walker C, Mitchell MD, Littlejohn M \& Roche JR 2011 Modification of endometrial fatty acid concentrations by the preimplantation conceptus in pasture-fed dairy cows. Journal of Dairy Research 78 263-269. (doi:10.1017/S0022029911000173)

Morris ST 2009 Economics of sheep production. Small Ruminant Research 86 59-62. (doi:10.1016/j.smallrumres.2009.09.019)

Nagy L, Tontonoz P, Alvarez JGA, Chen H \& Evans RM 1998 Oxidized LDL regulates macrophage gene expression through ligand activation of PPARy. Cell 93 229-240. (doi:10.1016/S0092-8674(00)81574-3)

Ng YH, Rome S, Jalabert A, Forterre A, Singh H, Hincks CL \& Salamonsen LA 2013 Endometrial exosomes/microvesicles in the uterine microenvironment: a new paradigm for embryo-endometrial cross talk at implantation. PLOS ONE 8 e58502. (doi:10.1371/journal. pone.0058502)

O'Sullivan SE 2007 Cannabinoids go nuclear: evidence for activation of peroxisome proliferator-activated receptors. British Journal of Pharmacology 152 576-582. (doi:10.1038/sj.bjp.0707423)

Rabiee AR, Breinhild K, Scott W, Golder HM, Block E \& Lean IJ 2012 Effect of fat additions to diets of dairy cattle on milk production and components: a meta-analysis and meta-regression. Journal of Dairy Science 95 3225-3247. (doi:10.3168/jds.2011-4895)

Racicot K, Schmitt A \& Ott T 2012 The myxovirus-resistance protein, $M X 1$, is a component of exosomes secreted by uterine epithelial cells. American Journal of Reproductive Immunology 67 498-505. (doi:10.1111/j.1600-0897.2012.01109.x)

Ray PD, Huang B \& Tsuji Y 2012 Reactive oxygen species (ROS) homeostasis and redox regulation in cellular signaling. Cellular Signaling 24 981-990. (doi:10.1016/j.cellsig.2012.01.008)

Record M, Carayon K, Poirot M \& Silvente-Poirot S 2014 Exosomes as new vesicular lipid transporters involved in cell-cell communication and various pathophysiologies. Biochimica et Biophysica Acta 1841 108-120. (doi:10.1016/j.bbalip.2013.10.004)

Ribeiro ES, Galvão K, Thatcher WW \& Santos JEP 2012 Economic aspects of applying reproductive technologies to dairy herds. Animal Reproduction 9 370-387.

Ribeiro ES, Greco LF, Bisinotto RS, Lima FS, Thatcher WW \& Santos JEP 2016a Biology of preimplantation conceptus at the onset of elongation in dairy cows. Biology of Reproduction 94 97. (doi:10.1095/ biolreprod.115.134908)

Ribeiro ES, Gomes G, Greco LF, Cerri RLA, Vieira-Neto A, Monteiro PLJ Jr, Lima FS, Bisinotto RS, Thatcher WW \& Santos JEP 2016b Carryover effect of postpartum inflammatory diseases on developmental biology and fertility in lactating dairy cows. Journal of Dairy Science $\mathbf{9 9}$ 2201-2220. (doi:10.3168/jds.2015-10337)

Rodgers JC, Bird SL, Larson JE, DiLorenzo N, Dahlen CR, DiCostanzo A \& Lamb GC 2012 An economic evaluation of estrous synchronization and timed artificial insemination in suckled beef cows. Journal of Animal Science 90 4055-4062. (doi:10.2527/jas.2011-4836)

Rodney RM, Celi P, Scott W, Breinhild K \& Lean IJ 2015 Effects of dietary fat on fertility of dairy cattle: a meta-analysis and meta-regression. Journal of Dairy Science 98 5601-5602. (doi:10.3168/jds.2015-9528)

Ruiz-González I, Xu J, Wang X, Burghardt RC, Dunlap KA \& Bazer FW 2014 Exosomes, endogenous retroviruses and toll-like receptors: pregnancy recognition in ewes. Reproduction 149 281-291. (doi:10.1530/REP-140538)

Saatchi M, Garrick DJ, Tait RG Jr, Mayes MS, Drewnoski M, Schoonmaker J, Diaz C, Beitz DC \& Reecy JM 2013 Genome-wide association and prediction of direct genomic breeding values for composition of fatty 
acids in Angus beef cattle. BMC Genomics 14 730. (doi:10.1186/14712164-14-730)

Santos JEP, Thatcher WW, Chebel RC, Cerri RLA \& Galvão KN 2004 The effect of embryonic death rates in cattle on the efficacy of estrus synchronization programs. Animal Reproduction Science 82 513-535. (doi:10.1016/j.anireprosci.2004.04.015)

Santos JEP, Bilby TR, Thatcher WW, Staples CR \& Silvestre FT 2008 Long chain fatty acids of diet as factors influencing reproduction in cattle. Reproduction in Domestic Animals 43 23-30. (doi:10.1111/ rda.2008.43.issue-s2)

Schaiff WT, Barak Y \& Sadovsky Y 2006 The pleiotropic function of PPAR $\gamma$ in the placenta. Molecular Cell Endocrinology 249 10-15. (doi:10.1016/j. mce.2006.02.009)

Schaiff TW, Knapp FF Jr, Barak Y, Biron-Shental T, Nelson MD \& Sadovsky Y 2007 Ligand-activated PPARg alters placental morphology and placental fatty acid uptake in mice. Endocrinology 148 3625-3634. (doi:10.1210/ en.2007-0211)

Shalom-Barak T, Zhang X, Chu T, Schaiff WT, Reddy JK, Xu J, Sadovsky Y \& Barak Y 2012 Placental PPAR $\gamma$ regulates spatiotemporally diverse genes and a unique metabolic network. Developmental Biology 372 143-155. (doi:10.1016/j.ydbio.2012.08.021)

Shay KP, Moreau RF, Smith EJ, Smith AR \& Hagen TM 2009 Alphalipoic acid as a dietary supplement: molecular mechanisms and therapeutic potential. Biochimica et Biophysica Acta 1790 1149-1160. (doi:10.1016/j.bbagen.2009.07.026)

Silvestre FT, Carvalho TSM, Francisco N, Santos JEP, Staples CR, Jenkins TC \& Thatcher WW 2011 Effects of differential supplementation of fatty acids during the peripartum and breeding periods of Holstein cows: I. Uterine and metabolic responses, reproduction, and lactation. Journal of Dairy Science 94 189-204. (doi:10.3168/jds.2010-3370)

Skjerven O 1956 Phosphatase, fat, and carbohydrate content of normal bovine endometrium. Biopsy studies of cyclic variations. Fertility and Sterility 7 31. (doi:10.1016/s0015-0282(16)32225-7)

Spencer TE, Johnson GA, Bazer FW \& Burghardt RC 2004 Implantation mechanisms: insights from the sheep. Reproduction 128 657-668. (doi:10.1530/rep.1.00398)

Spencer TE, Forde N, Dorniak P, Hansen TR, Romero JJ \& Lonergan P 2013 Conceptus-derived prostaglandins regulate gene expression in the endometrium prior to pregnancy recognition in ruminants. Reproduction 146 377-387. (doi:10.1530/REP-13-0165)

Staples CR, Burke JM \& Thatcher WW 1998 Influence of supplemental fats on reproductive performance of lactating cows. Journal of Dairy Science 81 856-871. (doi:10.3168/jds.S0022-0302(98)75644-9)
Subra C, Grand D, Laulagnier K, Stella A, Lambeau G, Paillasse M, De Medina P, Monsarrat B, Perret B, Silvente-Poirot S et al. 2010 Exosomes account for vesicle-mediated transcellular transport of activatable phospholipases and prostaglandins. Journal of Lipid Research $\mathbf{5 1}$ 2105-2120. (doi:10.1194/jlr.M003657)

Theurer ML, Block E, Sanchez WK \& McGuire MA 2009 Calcium salts of polyunsaturated fatty acids deliver more essential fatty acids to the lactating dairy cow. Journal of Dairy Science 92 2051-2056. (doi:10.3168/jds.2008-1276)

Thompson IM, Cerri RLA, Kim IH, Ealy AD, Hansen PJ, Staples CR \& Thatcher WW 2012 Effects of lactation and pregnancy on metabolic and hormonal responses and conceptus and endometrial gene expression of Holstein dairy cattle. Journal of Dairy Science 95 5645-5656. (doi:10.3168/jds.2011-5113)

Ulbrich SE, Schulke K, Groebner AE, Reichenbach HD, Angioni C, Geisslinger G \& Meyer HH 2009 Quantitative characterization of prostaglandins in the uterus of early pregnant cattle. Reproduction 138 371-382. (doi:10.1530/REP-09-0081)

Valour D, Degrelle SA, Ponter AA, Giraud-Delville C, Campion E, Guyader-Joly C, Richard C, Constant F, Humblot P, Ponsart C et al. 2014 Energy and lipid metabolism gene expression of D18 embryos in dairy cows is related to dam physiological status. Physiological Genomics 46 39-56. (doi:10.1152/physiolgenomics.00091.2013)

Wieser F, Waite L, Depoix C \& Taylor RN 2008 PPAR Action in human placental development and pregnancy and its complications. PPAR Research 2008 1-14. (doi:10.1155/2008/527048)

Woclawek-Potocka I, Komiyama J, Saulnier-Blache JS, Brzezicka E, Bah MM, Okuda K \& Skarzynski DJ 2009 Lysophosphatic acid modulates prostaglandin secretion in the bovine uterus. Reproduction 137 95-105. (doi:10.1530/REP-08-0209)

Wooding FB 1992 Current topic: the synepitheliochorial placenta of ruminants: binucleate cell fusions and hormone production. Placenta 13 101-113. (doi:10.1016/0143-4004(92)90025-O)

Wordinger RJ, Dickey JF \& Ellicott AR 1977 Histochemical evaluation of the lipid droplet content of bovine oviductal and endometrial epithelial cells. Journal of Reproduction and Fertility 49 113-114. (doi:10.1530/ jrf.0.0490113)

Received 1 March 2016

First decision 1 April 2016

Revised manuscript received 18 May 2016

Accepted 17 June 2016 